\title{
Contacto de lenguas a través de la asimilación del vocabulario indígena en los textos cronísticos alemanes del siglo XVI: Philipp von Hutten y Ulrich Schmidel.
}

\author{
Cristina Santana Quintana \\ Universidad de las Palmas de Gran Canaria (IATEXT)
}

La presencia de los viajeros alemanes Philipp von Hutten y Ulrich Schmidel en territorios americanos del siglo XVI (Argentina, Venezuela y Paraguay) nos llevó a preguntarnos en un estudio de caso cómo se introducen los indigenismos léxicos en sus crónicas y cuál es el índice de gradación; si utilizan los mismos criterios que los textos cronísticos españoles del siglo XVI y si existe alguna tendencia peculiar. Desde el punto de vista del contacto de lenguas esta aportación gira en torno al estudio entre las lenguas nativas y las interferencias en el léxico alemán que aparecen en el corpus de las obras seleccionadas, lo que nos ayuda a comprender mejor el proceso de contacto de lenguas y de culturas, constituyendo un aporte significativo a los estudios coloniales. Las crónicas de Philipp von Hutten ${ }^{1}$ y Ulrich Schmidel ${ }^{2}$ desvelan sus experiencias en territorios americanos durante el siglo XVI y el consiguiente encuentro con diversos pueblos que hablaban lenguas incomprensibles para los recién llegados. Este trabajo se centra en el análisis de sus obras correspondientes al periodo 1534 y 1554 elegidas principalmente porque tienen un gran valor histórico.

Philipp von Hutten (1505-1546) participó como capitán entre 1535 y 1538 en una exploración a América financiada por la compañía alemana de los Welser para la búsqueda de oro. A finales de 1540, fue nombrado por Carlos I de España capitán general de Venezuela. En una segunda expedición que dirigió entre 1541 y 1546, y tras constantes enfrentamientos entre los mandos alemanes y la tropa española fue derrotado, capturado y asesinado por el español Juan de Carvajal. Tras el asesinato de Hutten y del joven Welser se puede dar de hecho por terminada la colonización alemana de Venezuela, aunque legalmente no se marcó su punto final hasta 1559. Sus vivencias quedaron reflejadas en las cartas y los diarios de Philipp von Hutten de los años 1535 a 1541. Sin embargo, hay que señalar que estas cartas forman parte de las correspondencias que escribía a sus familiares y amigos, y por tanto no fueron escritos para un amplio público, por lo que se denota la familiaridad con la que escribía y el círculo privado a los que estaban destinadas. La prolongada estancia de Philipp von Hutten en América y su participación en dos importantes expediciones por zonas hasta entonces casi totalmente desconocidas confieren 
a sus cartas un notable valor documental, y representan el primer texto sobre América escrito por un testigo presencial alemán (Ribas, 2005).

Ulrich Schmidel (1510-1579) se alistó como soldado a bordo de buques de agentes comerciales alemanes que acompañan a Pedro de Mendoza a la Indias Occidentales, y participó durante mucho tiempo en la conquista de la región Río de la Plata bajo el mando de diferentes líderes como Mendoza, Juan de Ayolas, Alvar Núñez Cabeza de Vaca y Domingo Martoñez de Irala. Después de veinte años regresó a su tierra natal donde escribió las memorias de sus viajes (1567), que dio como resultado un texto escrito en una mezcla de alemán, espańol y nativo americanas. Su testimonio es valioso porque proviene de un conquistador no español que a su vez publica fuera de España, y porque representa una de las primeras crónicas de los habitantes y territorios que luego compondrán las actuales Argentina y Paraguay. Entre los escritores destacados de los primeros esfuerzos de colonización en el Río de la Plata, se encuentra el testimonio conocido de Ulrich Schmidel (1510_1579), un mercenario alemán que presencio la empresa rioplatense casi de principio a fin. Cuenta sus experiencias en un libro publicado en Fráncfort en 1567 con el título de Reise nach Süd-Amerika in den Jahren 1534 bis 1554 . Finalmente, se debe mencionar a Ruy Díaz de Guzmán autor de La Argentina, que circuló en copias manuscritas desde 1612 hasta 1835, año de su primera impresión. Este autor afirma que la importancia de este documento para la historia cultural de Argentina se confirma por la existencia de un estudio biográfico sobre Schmidel de Federico Kirbus y Nicolás Cócaro, 1948: Utz Schmidl; su vida, sus viajes, su obra. Por este motivo es considerado como uno de los testimonios más importantes de los primeros años de la conquista del Río de la Plata, además de destacar como obra de referencia para la conquista de Venezuela (Hüffer, 1950; Goodwin, 2007).

La importancia de la presencia de estos viajeros alemanes en territorios españoles en la América del siglo XVI (Venezuela, Argentina y Paraguay), permite ofrecer un estudio novedoso sobre un área geográfica menos investigada desde el punto de vista léxico y basada en un material fuertemente cohesionado. El interés de estos textos reside, por otro lado, en que nos ofrecen una traslación de la perspectiva directa de los autores a través de sus experiencias personales con la incorporación de nuevas palabras y vocablos, lo que nos permite llevar a cabo un análisis de la asimilación y registro de esas voces. Philipp von Hutten y Ulrich Schmidel tienen la ventaja de disfrutar de una mayor libertad para componer y escribir su historia, ya que sus obras no corresponden a los típicos documentos cronísticos que debían justificarse ante la administración, a los textos propagandísticos de la expansión de la Corona. Gracias a sus crónicas podemos reconstruir el mundo de las colonias dejando al margen las excéntricas heroicidades de los cronistas oficiales, obcecados en alabar cada movimiento de los nobles caballeros. Las crónicas están escritas desde la parcialidad y el subjetivismo, y los relatos se limitan casi exclusivamente a la sucesión cronológica de hechos, así como a mostrar los trabajos y sufrimientos experimentados en el Nuevo Mundo. En ambos autores no encontramos ni un interés historicista, ni afanes literarios, sino más bien la narración de aventuras vividas, de marcado carácter oral, en la que abundan las comparaciones entre la nueva realidad americana y el mundo conocido, es decir, la Alemania de su tiempo. A pesar de que narran una serie de reveses e insubordinaciones, sus historias expresan una notable confianza en la empresa de la 
conquista y de la colonización, pero en ningún caso se trata de los relatos del fracaso o de rebelión que aparecen en la segunda fase de la conquista de América.

Sobre los trabajos previos relativos a los indigenismos en los textos de viajeros alemanes a América en el siglo XVI podemos destacar dos trabajos. En primer lugar, el estudio realizado por P. M. Palmer (1933, 1939), que proporciona uno de los primeros análisis sobre las palabras influenciadas por el Nuevo Mundo y encontradas en textos alemanes desde 1742 hasta 1800 . Su intención se basa más bien en determinar cómo el vocabulario alemán se ha visto enriquecido por el contacto de los alemanes con el Nuevo Mundo, y de esta manera justificar la necesidad en ese momento de llevar a cabo un diccionario comparable al Nuevo Diccionario Inglés. El otro trabajo de R. Ribas (2005) se centra en los factores que determinan la forma que las manifestaciones de la conciencia lingüística adoptan en los textos de los alemanes, llegando a la conclusión de una presencia de una clara conciencia de la propia lengua asociada a una creciente identidad nacional alemana y al sentimiento de identidad cultural.

De hecho, se han llevado a cabo pocos estudios sobre las incorporaciones léxicas en los textos alemanes durante el siglo XVI si los comparamos con las investigaciones en textos españoles. Se han realizado muchas investigaciones sobre las incorporaciones de préstamos indígenas en textos españoles durante los siglos XVI y XVII desde distintas perspectivas. Los estudiosos han diferenciado los textos cronísticos a través del número de indigenismos léxicos que utilizan, es decir, si existe una preferencia por las voces taínas o nahuas, otros prefieren analizar los mecanismos discursivos hasta proponer una gradación basada en el proceso natural de la adopción y la palabra de transmisión en el análisis de estos textos en relación con la integración de la terminología indígena.

La importancia de la presencia de estos viajeros alemanes en territorios españoles en la América (Argentina, Venezuela y Paraguay) del siglo XVI y la falta de estudios existentes sobre el contacto con lenguas indígenas por parte de autores alemanes de esta época nos llevaron plantearnos las siguientes preguntas: 1) cómo introducen los indigenismos léxicos en sus crónicas y cuál es el índice de gradación siguiendo las últimas aportaciones sobre el tema; 2) si emplean los mismos criterios a la hora de utilizar el indigenismo léxico y qué aportan los textos cronísticos de alemanes del siglo XVI en comparación con los textos españoles y 3) si existe alguna tendencia peculiar a la hora de incorporar los préstamos en sus crónicas y si ayudan a comprender mejor el proceso de contacto de lenguas y culturas.

Con el fin de responder a las preguntas en un estudio de caso nos proponemos primeramente confeccionar un repertorio de indigenismos como material, y para establecer los mecanismos discursivos usados para reproducir el significado de los préstamos se analizarán dichas incorporaciones indígenas eligiendo como método un índice de gradación que hace posible medir en cada autor y grupo de vocablos su aparición. Este índice de valoración con una gradación fundamentada en el proceso natural de adopción y transmisión de términos ya ha sido utilizado por otros autores que estudian las incorporaciones de préstamos indígenas en textos españoles durante los siglos XVI y XVII como ya nombramos anteriormente. Este método nos permite averiguar en qué fase de asimilación se encuentra el indigenismo incorporado en los textos, y mostrar de qué manera se adaptan los nuevos vocablos. Nosotros lo hemos ajustado al idioma alemán, y según este concepto y para que resulte eficaz, los índices deben referirse siempre a un 
corpus concreto, en nuestro caso a dos autores, a dos obras, a un periodo histórico y a grupo de términos.

En la tabla 1 se puede observar el valor de cada índice que describe el grado de incorporación de los indigenismos teniendo en consideración los siguientes valores: consideraremos como préstamos indígenas nivel de incorporación 1 a esas palabras poco conocidas de las que es necesaria una breve explicación descriptiva o una comparación con un objeto familiar para los lectores y a la que se añade una calidad específica. Para el nivel 2 están representados aquellos ejemplos que se acompañan de una voz alemana través de las conjunciones o/y (que no expresan los valores exclusión, ni de adición, respectivamente). El nivel 3 de asimilación está representado por el uso indistinto en los textos para aquellos términos de diferentes orígenes que son considerados como equivalentes. Para alcanzar el nivel 4 en el proceso de incorporación, el término debe ser utilizado principalmente para designar el objeto que nombra, siendo el fenómeno común para las palabras ampliamente utilizadas. El nivel 5 se asemeja al nivel 4 e incluye préstamos indígenas que designan referentes adaptados a nuevos contextos culturales. Otro aspecto de este nivel 5 lo encontramos en indigenismos que nombran realidades y objetos muy distintos a los de la cultura originaria.

Tabla 1

\begin{tabular}{cl}
\hline Índice & Descripción del grado de incorporación \\
\hline 0 & No aparece el indigenismo \\
1 & Se emplea pero siempre junto a una explicación \\
2 & Se empareja siempre con un término alemán que se considera sinónimo \\
3 & Se usa el término indígena o su sinónimo alemán indistintamente \\
4 & El indigenismo se usa sin ningún tipo de explicación o connotación en cualquier área \\
& geográfica con su significado inicial. \\
& El préstamo indígena aparece sin explicación en cualquier zona geográfica, pero ha ampliado \\
& su significado originario porque designa nuevos referentes.
\end{tabular}

En la tabla 2 se recoge la aplicación del índice de incorporación y origen de los indigenismos seleccionados en los textos de Philipp von Hutten, y en la tabla 3 los de Ulrich von Schmidel:

Tabla 2

Philipp von Hutten

\begin{tabular}{|c|c|c|c|}
\hline Indigenismo & $\begin{array}{l}\text { Origen de } \\
\text { las voces }\end{array}$ & $\begin{array}{c}\text { Grado de } \\
\text { incorporación }\end{array}$ & Texto y página del libro \\
\hline Canoas & $\begin{array}{l}\text { antillano } \\
\text { (taíno) }\end{array}$ & 4 & "Kament teglichs vil Indianer in Canoas zw vns" (100) \\
\hline $\begin{array}{l}\text { Cassab } \\
\mathrm{i}\end{array}$ & $\begin{array}{l}\text { antillano } \\
\text { (arahuaco) }\end{array}$ & 1 & $\begin{array}{l}\text { "Sie machen Brot aus einer Wurtzel ßo sie Cassabi nennen" } \\
(89) \\
\text { (Cazabí = cazabe) }\end{array}$ \\
\hline Cassicqen & antillano & 2 & "Fiengent an Cassicquen oder Obersten" (98) \\
\hline Cassicques & (caribe) & 4 & $\begin{array}{l}\text { "Informiert sich der Gouernador vonn den Cassicques des } \\
\text { Lands" (100) }\end{array}$ \\
\hline
\end{tabular}




\begin{tabular}{|c|c|c|c|}
\hline Casumbe & $\begin{array}{l}\text { antillano } \\
\text { (arahuaco) }\end{array}$ & 1 & $\begin{array}{l}\text { "Haben noch ain Manier vom Brot, das sy Casumbe } \\
\text { nennen" (57) } \\
\text { (Quería decir Cazabe pero escribe una palabra parecida al } \\
\text { cusumbe que es un coatí, un animal. }\end{array}$ \\
\hline Hamares & $\begin{array}{l}\text { antillano } \\
\text { (taíno) }\end{array}$ & 4 & $\begin{array}{l}\text { "so sy in Hamares tragen muesten" (59) } \\
\text { (Hamacas) }\end{array}$ \\
\hline Iucka & $\begin{array}{l}\text { antillano } \\
\text { (taíno) }\end{array}$ & 4 & $\begin{array}{l}\text { "Dan wiewol es Mahiz vnd Iucka genug hat, ßo hetten wir } \\
\text { doch sunst kain Refrigerio von Fleisch, Visch noch Saltz" } \\
\text { (102) } \\
\text { (Yuca) }\end{array}$ \\
\hline Manati & $\begin{array}{l}\text { antillano } \\
\text { (caribe o } \\
\text { arahuaco) }\end{array}$ & 1 & $\begin{array}{l}\text { "Tartschen von Läder auß aines Visch Haut, Manati } \\
\text { gennant" (85) }\end{array}$ \\
\hline $\begin{array}{l}\text { Mayz } \\
\text { Mahis } \\
\text { Mahiz }\end{array}$ & $\begin{array}{l}\text { antillano } \\
\text { (taíno) }\end{array}$ & $\begin{array}{l}1 \\
4 \\
4 \\
4\end{array}$ & $\begin{array}{l}\text { "Sy machen Brot von weissen Körnern, das sy Mayz } \\
\text { nennen" (57) } \\
\text { "vnd man fand Mayz wol auff drey Monat lang" (61) } \\
\text { "allen Orten Mahis, do sie Brot backen" (92); } \\
\text { "ßo hat es gut krefftich Brot im Land von Mabiz" (95) }\end{array}$ \\
\hline
\end{tabular}

\section{Tabla 3}

\begin{tabular}{|c|c|c|c|}
\hline \multicolumn{4}{|c|}{ Ulrich von Schmidel } \\
\hline Indigenismo & $\begin{array}{l}\text { Origen de } \\
\text { las voces }\end{array}$ & $\begin{array}{c}\text { Grado de } \\
\text { incorporación }\end{array}$ & Texto y página del libro \\
\hline Acare & guaraní & 1 & $\begin{array}{l}\text { "Acare ist ein großer Fisch, der hat eine harte Haut, daß } \\
\text { man ihn mit feiner Waffen fann wund hauen, noch mit } \\
\text { den indianischen Pfeifen schießen, und er tut den anderen } \\
\text { Fischen sehr viel Schadens" (78) } \\
\text { (Acare = yacaré = caimán) }\end{array}$ \\
\hline Batata & $\begin{array}{l}\text { antillano } \\
\text { (taíno) }\end{array}$ & 1 & $\begin{array}{l}\text { "ferner die Wurzel Batata, die sieht einem Apfel gleich, hat } \\
\text { auch denselben Geschmack" (43) }\end{array}$ \\
\hline Batates & $\begin{array}{l}\text { antillano } \\
\text { (taíno) }\end{array}$ & $\begin{array}{l}4 \\
4 \\
4\end{array}$ & $\begin{array}{l}\text { "und viel zu essen hätten, als türkisch Korn, Mandioka, } \\
\text { Batates un andere Wurz und Würzel" (52) } \\
\text { "Die haben als türkisch Korn, Mandiok, Mandi, Batates" } \\
\text { (76) } \\
\text { "Diese Nation hat großen Borrat an türkischem Korn, } \\
\text { Mandiok pepira, Mandiok poropi, Batates" (107-108) } \\
\text { (Plural de batata) }\end{array}$ \\
\hline $\begin{array}{l}\text { Canoas } \\
\text { Canoen }\end{array}$ & $\begin{array}{l}\text { antillano } \\
\text { (taíno) }\end{array}$ & $\begin{array}{l}4 \\
4 \\
4 \\
4 \\
4\end{array}$ & $\begin{array}{l}\text { "fuhen sie uns in Friedensweis zu auf Canoas" (27) } \\
\text { "hatten überaus viel Canoas" (33) } \\
\text { "die haben sehr viel Canoen" (76) } \\
\text { "so zogen mit uns von diesen Indianern zehn Canoen" (78) } \\
\text { "da kehrten gemeldte Surucusis mit ihren zehn Canoen } \\
\text { wieder heim zu ihrem Flecken" (78) }\end{array}$ \\
\hline
\end{tabular}




\begin{tabular}{|c|c|c|c|}
\hline Mais & $\begin{array}{l}\text { antillano } \\
\text { (taíno) }\end{array}$ & $\begin{array}{l}2 \\
2 \\
4\end{array}$ & $\begin{array}{l}\text { "Da gab Gott der Allmächtige feinen Segen, daß wir bei } \\
\text { ihnen fanden (wie uns war angezeigt worden) von dem } \\
\text { türkisch Korn oder Mais" (43) } \\
\text { "sie sollten so weit ziehen, als sie kunnten, und Indianer } \\
\text { suchen, die Mandioka und türkisch Korn (das ist Mais) } \\
\text { hätten" (72) } \\
\text { "diese haben zu essen Mandiok, Mais, Mandi, Padades, } \\
\text { Mandiok-Poropi und andere Wurzel" (78) }\end{array}$ \\
\hline Mandi & $\begin{array}{l}\text { antillano } \\
\text { (taíno) }\end{array}$ & $\begin{array}{l}1 \\
4 \\
4\end{array}$ & $\begin{array}{l}\text { "diese hatten türkisch Korn und Mandioka, und auch } \\
\text { andere Wurzeln, als Mandi, feind den Haselnüssel gleich" } \\
\text { (72) } \\
\text { "Die haben als türkisch Korn, Mandiok, Mandi" (76) } \\
\text { "diese haben zu essen Mandiok, Mais, Mandi,..." (78) } \\
\text { (Maní, cacahuete o mandubí) }\end{array}$ \\
\hline $\begin{array}{l}\text { Mandioka } \\
\text { Mandiok }\end{array}$ & guaraní & $\begin{array}{l}1 \\
1 \\
1 \\
4 \\
4\end{array}$ & $\begin{array}{l}\text { "Denn die haben türkisch Korn, Obst und eine Wurzel } \\
\text { Mandioka, da sie Wein von machen" (33) } \\
\text { "und viel zu essen hätten, als türkisch Korn, Mandioka" (52 } \\
\text { "diese hatten türkisch Korn und Mandioka, und auch } \\
\text { andere Wurzeln" (72) } \\
\text { "Die haben als türkisch Korn, Mandiok, Mandi,..." (76) } \\
\text { "diese haben zu essen Mandiok" (78) } \\
\text { (Mandioca) }\end{array}$ \\
\hline $\begin{array}{l}\text { Mandiok } \\
\text { poropi }\end{array}$ & guaraní & $\begin{array}{l}1 \\
1 \\
4\end{array}$ & $\begin{array}{l}\text { "und Mandiok poropi, hat einen Geschmack wie die } \\
\text { Käften"(43) } \\
\text { "diese haben zu essen Mandiok, Mais, Mandi, Padades, } \\
\text { Mandiok-Poropi und andere Wurzel" (78) } \\
\text { "Diese Nation hat großen Borrat an türkischem Korn, } \\
\text { Mandiok pepira, Mandiok poropi" (107-108) } \\
\text { (Pororó = rosetas de maíz) }\end{array}$ \\
\hline $\begin{array}{l}\text { Mandioka } \\
\text { pepira }\end{array}$ & guaraní & $\begin{array}{l}4 \\
1\end{array}$ & $\begin{array}{l}\text { "Aus Mandioka pepira machen die Indianer ihren Wein" } \\
\text { (43) } \\
\text { "Diese Nation hat großen Borrat an türkischem Korn, } \\
\text { Mandiok pepira" (107-108) } \\
\text { (La Pepirá que es la colorada y dulce, Poropí que es dulce) }\end{array}$ \\
\hline Nandu & guaraní & 2 & $\begin{array}{l}\text { "nach dem singen sie ungefährlich dreißig Hirchen und } \\
\text { zwanzig Straußen oder Nandu" (81) } \\
\text { (ñandú) }\end{array}$ \\
\hline
\end{tabular}

La diferencia en el grado de asimilación de cada relación se aprecia en la tabla siguiente:

Tras la lectura de los resultados de nuestro estudio se deduce que el recurso más frecuente $(64.3 \%)$ del que se sirven Philipp von Hutten y Ulrich Schmidel para denominar lo nuevo y poder transmitir esta nueva realidad es el uso del indigenismo sin ningún tipo de explicación sobre su naturaleza y dando las voces por conocidas en el texto al usarlas como vocabulario rutinario de sus narraciones (valor 4). Para considerar que un término ha alcanzado un grado 4 en su adopción debe ser usado mayoritariamente para designar el objeto que nombra. Es muy común en el caso de aquellos vocablos de uso general: coca, canoa, hamaca, macana, aguacate, etc. De los catorce indigenismos abordados y gradados según su proceso de adopción, nueve resultan ser de origen antillano 
- gran parte palabras taínas (canoa, cacique, maiz, hamaca, yuca, manatí, batata, maní, cazabe) -, que son las que tienen en mayor medida el valor de gradación 4. Se trata de palabras que en los inicios de la colonización se consideraban como imprescindibles, y que pronto se advierte que ya no era necesario usar los mecanismos textuales para su uso general en los textos coloniales (Hernández, 1996; Tabernero, 2011). Los historiadores alemanes se comportaban siempre como extranjeros entre los españoles, por lo cual es muy probable que adoptasen la mayor parte de los indigenismos de fuentes españolas o a través de la lengua de las naciones implicadas en la conquista de la época. Cierto es que la lengua alemana tampoco era la que usaban para comunicarse con sus compañeros, que eran en su mayoría españoles, portugueses u holandeses. Por lo que la mayoría de la incorporación de los indigenismos abordados de origen antillano en los textos depende antes de un proceso de contacto con hispanos que con indígenas.

En los textos encontramos seguidamente $(25 \%)$ el empleo primero de la palabra indígena con una explicación (valor 1), utilizando con mayor frecuencia el recurso comparativo de la estructura "ser + como + vocablo alemán". Muy pocos (10.7 \%) son los vocablos que aparecen en los textos con sus posibles sinónimos y por lo que se les puede adjudicar el valor 2 . Se ha podido observar que los autores no inventan una palabra en alemán para las formas de reproducción de la lengua ajena, sino que por lo general recurren al uso de los indigenismos para describir la vida cotidiana que aparecen con frecuencia en la búsqueda de comida, prioritaria para la supervivencia. En ninguno de los textos revisados de estos autores se usa el término indígena o su sinónimo alemán indistintamente (valor 3), ni el préstamo indígena aparece sin explicación ampliando su significado originario al designar a nuevos referentes (valor 5).

En la mayoría de las ocasiones, los autores intentan acercar los términos extraños a sus compatriotas por medio de las comparaciones y en términos de igualdad, cuando vuelven a nombrarlos dan por supuesto que el lector ya sabe de qué se trata, de modo que o bien remite a lo ya dicho o bien escriben el nombre sin más. Sin embargo, al equiparar la palabra europea a la palabra nativa, solo se están teniendo en cuenta las similitudes entre ambos referentes y se deja de lado las diferencias que justifican la existencia de dos términos. Así ocurre, por ejemplo, en el fragmento de Ulrich Schmidel en el cual se refiere al ñandú equiparándolo al avestruz y donde el autor se limita a establecer la identidad entre ambos términos y no las diferencias. Por otro lado, se refleja el esfuerzo por reproducir un sonido nuevo y por adaptarlo a las convenciones del propio sistema lingüístico. De este modo surgen diferentes variaciones de una misma palabra: Cassicques, Cassicqen, Mahis, Mahiz, Mayz, Canoas, Canoen, Mandiok, Mandioka. E incluso confunde la palabra que oye con otra como en el caso de Casumbe. El autor quería hacer referencia al Cazabe pero escribe una palabra parecida, Cusumbe que es un coatí, un animal.

Si revisamos el origen de las voces durante el proceso de incorporación de ambos autores observamos que diez son de origen antillano: del arahuaco cazabe y cusumbe, del caribe cacique, y en especial las palabras que han sido prestadas a más idiomas vienen del taíno como canoa, maiz, batata, hamaca, yuca, manatí y maní. Pero no es de extrañar, ya 
que en los orígenes de los términos indígenas asimilados en la primera mitad del siglo XVI eran en su gran mayoría de origen antillano, sobre todo los tainismos que habían alcanzado ya un fuerte arraigo en el habla de los conquistadores, y estaban presentes en las crónicas de Indias escritas en español (Mejías, 1980; Cáceres-Lorenzo, 2012, 2013).

Es conocido que la presencia alemana en América no tenía ambiciones coloniales propias, sino que su objetivo era la adquisición de riquezas lo más rápida y lo menos costosamente posible, y del mismo modo que no existía un intento de colonización geográfica, tampoco lo había de colonización lingüística. Philipp von Hutten y Ulrich von Schmidel eran unos extrańos no solo para los indígenas, sino para los propios colonos. Dada la poca participación directa de los alemanes en América, ya que se calcula que los alemanes constituían escasamente entre un $0,3 \%$ y un $0,6 \%$ de la población europea en América hacia la mitad del siglo XVI (Ribas, 2005) las palabras que se producen por primera vez en la época de los siglos XVI y XVII estaban especialmente influenciadas por portugueses, holandeses, pero sobre todo por espańoles. Este es el motivo por el que en sus textos aparecen tantas palabras mezcladas con estos idiomas para describir la realidad de la cultura indígena.

En el trabajo de Ulrich von Schmidel también aparecen los préstamos de palabras del taíno, pero resalta la incorporación de lexemas guaraníes como yacaré, mandioca, pororó, pepirá y ñandú. La razón puede estribar en que su obra relata acontecimientos de su visita a Paraguay, zona geográfica sudamericana donde prevalecía la lengua guaraní. También influye el hecho de que - al igual que muchos españoles - había aprendido la lengua indígena por inmersión al pasar una larga temporada con ellos y verse obligado a comunicarse con los nativos para conseguir comida y poder subsistir. Hay que poner de relieve que estos lexemas no eran usuales para el autor, pues el grado de integración de estas palabras es de valor 1, es decir, que las emplea junto a una explicación. Si comparamos estos textos cronísticos alemanes del siglo XVI con los textos espańoles y si utilizamos los mismos criterios de valoración de asimilación del léxico indígena podemos destacar que en general queda evidente que los cronistas alemanes estudiados tienen predilección por el préstamo taíno como los autores españoles, según indican los estudios previos. En su mayoría se trata de productos vegetales que no tenían nombre en castellano y pronto se les aplicó la voz americana.

Como respuesta a la pregunta principal de nuestro trabajo 1) cómo se introducen los indigenismos léxicos en sus crónicas y cuál es el índice de gradación podemos indicar que los cronistas alemanes Philipp von Hutten y Ulrich von Schmidel adoptan varias estrategias para reproducir sus significados, pero destaca que la estrategia más empleada es la de aplicar el término indígena cuando no tiene un sinónimo claro y está perfectamente asimilado (nivel 4). Es el caso de canoa, cacique, hamaca, yuca, maíz, batata, canoa y maní, que son aceptadas como nuevas palabras sin tratar de crear una palabra descriptiva en su propio idioma. Los indigenismos menos usuales - entre ellos los de origen guaraní en el caso de Ulrich von Schmidel -, los incorpora en sus textos primero mostrando las comparaciones con su mundo originario (valor 1) para luego dar en muchos casos paso al término directamente sin ningún tipo de explicación (de nuevo el valor 4). De este criterio de selección en el uso de los indigenismos se desprende el interés comprender la 
inserción de los vocablos de origen indígena americano en los cronistas alemanes Philipp von Hutten y Ulrich von Schmidel.

Con respecto al objetivo 2) de este trabajo, si revisamos este método utilizado en autores españoles de la misma época y comparamos los resultados sobre el grado de asimilación de los indigenismos en los textos alemanes estudiados, se puede deducir que el sistema utilizado por ambos grupos para introducir los indigenismos es similar: el empleo de un gran número de términos cuyo índice se considera valor 4, usar el indigenismo sin ningún tipo de explicación sobre su naturaleza y dando las voces por conocidas en el texto al usarlas como vocabulario rutinario de sus narraciones. En la mayoría de los casos se trata de productos vegetales que no tenían nombre en castellano y pronto se les aplicó la voz antillana. Es importante resaltar el texto de Ulrich von Schmidel, dado que con respecto a los textos espańoles que hemos comparado aporta una peculiaridad diferente, ya que incorpora lexemas guaraníes de la zona del Paraguay, zona poco estudiada y quizás por este motivo desconocida; unido al hecho de que las áreas colonizadas de Mesoamérica y Sudamérica en el siglo XVI reflejan una integración más lenta de los indigenismos léxicos con respecto al periodo inicial antillano (Bravo García y Cáceres-Lorenzo, 2013).

Finalmente, sobre nuestra tercera pregunta 3) si existe alguna tendencia peculiar a la hora de incorporar los préstamos en sus crónicas, se observa que los indigenismos utilizados en las crónicas de Philipp von Hutten y Ulrich von Schmidel servían para nombrar lo hasta entonces desconocido, es decir, para llenar los vacíos lingüísticos y culturales de la misma forma que en los textos españoles, ya que entendieron muy pronto la importancia de comprender la cultura de los nativos y de designar las nuevas realidades americanas como elementos que remiten a la cultura. Pero aparte de llenar alguna laguna léxica, desempeñaban la "función" de conferir color local al mensaje así como de dotar de autenticidad a las cosas descritas y expuestas y de ańadir prestigio a los escritos con la intención de verificar que su estancia fue real.

El análisis llevado a cabo nos ha permitido conocer las claves del peso de cada aporte según los testimonios de nuestros viajeros y de entender los procesos de contacto de lenguas y culturas. Las crónicas de Philipp von Hutten y Ulrich Schmidel, en las que se relata lo visto y vivido, son textos en los que con frecuencia se describe a los aborígenes y se da cuenta de sus costumbres y tradiciones, religiones y ritos, además de reseñar con detalle el paisaje, la naturaleza, la flora y la fauna. Para poder dar a conocer esta nueva realidad ante la cual se encontraban, los cronistas analizados tenían en ocasiones que valerse de palabras indígenas para designar lo nuevo, puesto que en alemán no existía un vocablo para el referente en cuestión. De ahí que los autores empleen en sus relatos e historias un repertorio de voces amerindias. Se logra entender que las transferencias de rasgos procedentes de lengua aborígenes no sean exactas, que contengan errores e inexactitudes como ya ocurre en los textos españoles de esta época, por el hecho de que las crónicas citadas son de una fecha tan temprana. Bien es verdad que la temática que hemos encontrado en los préstamos hallados no es muy novedosa en el ámbito de los estudios filológicos, ya que aportan fragmentariamente información léxica limitada a temas como la flora y la fauna. No obstante, hay que recordar que en el momento de la llegada de los europeos a los territorios de Argentina, Venezuela y Paraguay, estos estaban ocupados por grupos indígenas ágrafos que si bien no desconocían la práctica de la agricultura, 
dependían esencialmente de la pesca, de la recolección y de la caza para subsistir, por lo que es deducible que el vocabulario prestado se limite a este campo semántico.

Los resultados de nuestro estudio parecen confirmar que los autores alemanes integraron los indigenismos debido a la necesidad de comunicación que forzó a los protagonistas, tanto a los europeos como a los indígenas, a escuchar, repetir y aprender las extrańas voces de su interlocutor y a emplear distintos mecanismos para lograr el mutuo entendimiento. Sin embargo, detrás de esa necesidad de expresividad, sobre todo de nuevas denominaciones, podría existir lo que se denomina "débil motivación" (Sala, 1988), es decir, la arrogancia de la sociedad colonial ante los pueblos dominados y que redujo su interés en las culturas indígenas hacia lo indispensable, principalmente en cuanto a sus conocimientos de la naturaleza (flora y fauna); una razón más para que no se integraran vocablos de otros dominios semánticos.

Según la teoría constructivista del contacto de lenguas (Zimmermann, 2011), cada percepción y creación de significado es individual, es decir, según el concepto individual que se tiene frente a la realidad basada en factores ideológicos, de mitos o creencias religiosas, así como de "errores", que pueden influir en el momento del contacto de lenguas. Uno de esos factores puede ser incluso inconsciente, la actitud de los hablantes de una lengua con supremacía frente a una lengua "inferior". En nuestro caso estamos ante una cultura europea con un lenguaje escrito y con un sentimiento de superioridad ante una población de indígenas. Hemos podido observar que los autores alemanes no tomaron como préstamos muchas palabras de las lenguas indígenas, sino que la integración lingüística de lo nuevo se llevo a cabo a través de descripciones o de transferencias buscando un significante de la otra lengua para algo desconocido hasta entonces y relevante para su vida. Parece que no necesitaban otra transferencia más de la lengua local para la comunicación entre ellos, y que quizás hace referencia a una actitud de defensa de la integridad de la propia lengua en una situación de contacto cultural, así como el sentimiento de supremacía y de una creciente identidad nacional alemana.

Por tales motivos, no adquirieron la lengua amerindia, ni tampoco el bilingüismo, sino más bien llevaron a cabo una integración lingüística de lo nuevo sea en forma de expresiones metafóricas, descripciones o transferencias bien contraladas. Los préstamos revisados se han podido encontrar integrados morfológicamente, sin mayor explicación o con alguna aclaración indicando que se trata de un referente peculiar del mundo del "otro" y ajeno al mundo europeo. Philipp von Hutten y Ulrich Schmidel utilizan paráfrasis de un significado pero no solo porque los debieron considerar poco conocidos a fines del siglo XVI, sino porque la aclaración marca distancia entre el mundo europeo y el americano. En definitiva parece ser que la mayor parte de los préstamos se utilizaron para describir el mundo y el contexto indígena, el mundo del "otro", empleando casi siempre los términos de la lengua del otro".

Los textos de Philipp von Hutten y Ulrich Schmidel tienen un gran valor histórico porque son testigos directos del asentamiento en América y por hallarse escritos en primera persona y contar sus vivencias personales. La situación, en la que se encuentran nuestros autores, les obliga de alguna manera a ajustar su forma de hablar, acomodándose al entorno que les rodea como un medio de expresar valores, actitudes e intenciones hacia los demás. Con este trabajo no se pretende definir parte de la historia de una lengua, sino las 
relaciones que surgen entre las lenguas a través de los préstamos léxicos adoptados durante un periodo histórico compartido. En sus testimonios, nuestros autores van nombrando las cosas a su paso, sin detenerse en el detalle ni en buscar intencionadamente lo indígena. Este carácter distintivo hace que este tipo de textos tengan un valor como testimonio directo e indiscutible dentro de los estudios coloniales.

\section{Notas}

${ }^{1}$ Las cartas y documentos de los años 1534 y 1541 en donde informa como primer alemán sobre las relaciones entre América y Europa: 1. Newe Zeytung: Bericht des Philipp von Hutten uber die Ausreise aus Europa und die Uberfahrt nach Amerika 1534-1535, uber die Teilnahme am Zug des Georg Hohermuth von Speyer 1535-1538 in das Landesinnere von Tierra firme und uber die aufsehenerregendsten Ereignisse der spanischen Konquista in der Neuen Welt 1522-1542. 2. Philipp von Hutten an den Kaiserlichen Rat Matthias Zimmermann zu Breda: Brief aus San Germän de Puerto Rico vom 28 Januar 1535. 3. Philipp von Hutten an den Kaiserlichen Rat Matthias Zimmermann: Brief aus Coro vom 23 Februar 1535. 4. Philipp von Hutten an den Kaiserlichen Rat Matthias Zimmermann: Brief aus Coro vom 30 Juli/30 Oktober 1538. 5. Philipp von Hutten an seinen Vater Bernhard von Hutten zu Birkenfeld: Brief aus Coro vom 20 Oktober 1538. 6. Philipp von Hutten an Georg Geuder zu Nurnberg: Brief aus Coro vom 20 Oktober 1538. 7. Philipp von Hutten an seinen Vater Bernhard von Hutten zu Birkenfeld: Brief aus Coro vom 31 März 1539. 8. Philipp von Hutten an seinen Bruder Moritz von Hutten: Brief aus Coro vom 16 Januar 1540. 9. Philipp von Hutten an seinen Bruder Moritz von Hutten: Brief aus Coro vom 6 Dezember 1540. 10. Philipp von Hutten an seinen Bruder Moritz von Hutten: Brief aus Coro vom 12 Dezember 1540. 11. Philipp von Hutten an seinen Bruder Wilhelm von Hutten zu Birkenfeld: Brief aus Coro vom 9 März 1541. 12. Philipp von Hutten an seinen Bruder Moritz von Hutten: Brief aus Coro vom 10 März 1541.

${ }^{2}$ Su relato aparece por primera vez en 1567 en la edición de Feyrabend en alemán. Schmidel, Ulrich, 1567: Wahrhaftige Historie einer wunderbaren Schiffahrt, welche Ulrich Schmidel von Straubing von 1534 bis 1554 in America oder Neuewelt bei Brasilia oder Rio della Plata getan. Mit Verbesserung der Städt-, Länder- und FlüßNamen, desgleichen mit einer notwendigen Landtafel, Figuren und anderer Erklärung gezieret nach der Edition des Levinus Hulsius, edición de Feyrabend. Schmidel, Ulrich, 1889: Reise nach Süd-Amerika. In den Jahren 1534 bis 1554, Langmantel: Valentin. Otras versiones revisadas: Schmidel Uldérico [Ulrich], 1881: Historia y descubrimiento del Río de la Plata y Paraguay, Buenos Aires: Mayo; Schmidel, Ulrich, 1986: Relatos de la conquista del Río de la Plata y Paraguay 1534-1554. Prólogo [traducción] y notas de Klaus Wagner, Madrid: Alianza Editorial, 9-22; Schmidel, Ulrich, 1948: Crónica del viaje a las regiones del Plata, Paraguay y Brasil, Trad. Edmundo Wernicke, Buenos Aires: Peuser. En 1599 en latín, en una edición de Levinus Hulsius, y en el mismo año en la séptima parte de los grandes viajes de Teodoro de Bry, tanto en latín como en alemán.

\section{Bibliografía}

Alvar López, Manuel. Americanismos en la "Historia“ de Bernal Díaz del Castillo. Madrid: Ediciones de cultura hispánica, 1990.

- España y América cara a cara. León: Editorial Bella Época, 1975.

Alvar Ezquerra. Vocabulario de indigenismos en las crónicas de Indias. Madrid: Consejo Superior de Investigaciones Científicas, 1997.

Frago Gracia, Juan Antonio. "Criterio filológico y edición de textos indianos: Sobre documentos de la nueva España." Romance Philology 53/1 (1999): 119-136.

Bastardín Candón, Teresa. Vocabulario indigena en la Historia de fray Bernardino de Sahagún. Fondo hispánico de lingüística y filología. Bern: Peter Lang, 2013.

Bravo García, E. M. y M. T. Cáceres Lorenzo. La incorporación del indigenismo léxico en los contextos comunicativos canario y americano (1492-1550). Bern: Peter Lang, 2011.

- Claves para comprender las crónicas de Indias. Madrid: McGraw-Hill/Interamericana de España, 2012.

. El léxico cotidiano en América a través de las relaciones geográficas de indias: Tierra firme y América del sur, s. XV. Bern (etc.): Peter Lang, 2013.

. "Estrategias comunicativas y tipos documentales en la selección de voces amerindias en el siglo XVI (1518-1559)." RILCE 30.1 (2014): 86-110. 
Buesa, Oliver y J. M. Enguita Utrilla. Léxico del español de América: su elemento patrimonial e indígena. Madrid: Mapfre, 1992.

Cáceres-Lorenzo, Maria Teresa. "Taino, Nahua and Quechua Lexicons in the Spanish Chronicles (14921648): A Comparative Study of Their Degree of Incorporation." Studia Neophilologica, Volume 84, Issue 2 (2012): 129-137.

. "Indoamericanismos de uso general en documentos españoles americanos (1502-1560): propuesta de clasificación y resultados." Bulletin of Spanish Studies: Hispanic Studies and Researches on Spain, Portugal and Latin America, Volume 90, Issue 7 (2013): 1079-1090.

- "Differentiation between Indigenous Loanwords in the Spanish American Lexicon." Bulletin of Hispanic Studies, 91:2 (2014): 117-126.

- "Dimensiones comunicativas del vocabulario nahua en las crónicas franciscanas: ¿̨Indicios de mestizaje lingüístico o estrategia evangélica de motolinía y sahagún.” Crítica Hispánica, 37/1 (2015), $7-25$.

Caillet Bois, Julio. La literatura colonial. Historia de la literatura argentina. Buenos Aires: Ediciones Peuser, 1958.

Enguita Utrilla, J. M. Para la historia de los americanismos léxicos. Frankfurt am Main: Peter Lang, 2004.

Félix Bolaños, Álvaro. "The Requirements of a Memoir: Ulrich Schmidel's Account of the Conquest of the River Plate (1536-54)." Colonial Latin American Review, Vol.11, 2 (2002): 231-250.

Foster, David William. "Ulrico Schmidel: Relatos de la conquista del Río de la Plata y Paraguay 15341554." Chasqui. Revista de Literatura Latinoamericana 20, 2 (1991): 73-77.

Frago Gracia, Juan Antonio. "Sobre la criollización del español de América: apuntes documentales y metodológicos., Boletín de Filología XXXVII (1998): 523-539.

García Loaeza, Pablo. "La conquista del Río de la Plata: Adversidad, esperanza y escritura." Hispania, 1, Vol.94, 4 (2011): 603-614.

Goodwin, R. T. C. "De lo que sucedió a los demás que entraron en las Indias': Álvar Núńez Cabeza de Vaca and the Other Survivors of Pánfilo Narváezs." Bulletin of Spanish Studies, Volume LXXXIV, Number 2, (2007): 147-173.

Hernández, Esther. Vocabulario en lengua castellana y mexicana de fray Alonso de Molina: Estudio de los indigenismos léxicos y registro de las voces españolas internas. Madrid: Consejo Superior de Investigaciones Científicas, 1996.

Hüffer, H. J. "Aus 1200 Jahren deutsch-spanischer Beziehungen. Ein Überblick." Romanistisches Jahrbuch, Vol. 3 (1950): 85-123.

Iglesia, Cristina. "Conquista y mito blanco." Cautivas y misioneros. Mitos blancos de la conquista, Cristina Iglesia y Julio Schvartzman (eds.), Buenos Aires: Catálogos Editora, 1987: 11-88.

Lope Blanch, J. M. Antillanismos en la Nueva España. Investigaciones sobre dialectología mexicana. México: UNAM, 1990.

—. Actitudes sociolingüisticas: México y España. Estudios De Lingüística: Universidad de Alicante, 1999.

López Morales, H. "Indigenismos en los textos cronísticos de Puerto Rico: índices de frecuencia y densidad." L. Quiroga Torrealba, M. Torrealba Lossi y P. Díaz Seijas, Estudios filológicos y lingüisticos: Homenaje a Angel Rosenblat en sus 70 años. Caracas: Instituto Pedagógico: 1974: 337-346.

Mejías, Hugo A. Préstamos de lenguas indígenas en el español americano del siglo XVII. México: Universidad Nacional Autónoma de México, 1980.

Palmer, Philip Motley. Der Einfluss der neuen Welt auf den deutschen Wortschatze 1492 - 1800. Heidelberg: Winter, 1933.

- Neuweltwörter im Deutschen. Heidelberg: Winter, 1939.

Ribas, Rosa. Testimonios de la conciencia lingüistica en textos de viajeros alemanes a América en el siglo XVI. Kassel: Reichenberger, 2005.

Rivarola, J. L. El español de América en su historia. Valladolid: Universidad de Valladolid, 2001.

Rojas, Ricardo, 1948: Historia de la literatura argentina. Ensayo filosófico sobre la evolución de la cultura en el Plata. Los coloniales, Segunda parte, Vol. 1., Buenos Aires: Editorial Losada.

Romero Gualda, María Victoria. Indoamericanismos léxicos en la crónica de Pedro Pizarro. Thesaurus: Boletín Del Instituto Caro y Cuervo 38, 1983.

Sala, Marius. El problema de las lenguas en contacto. México: Universidad Nacional Autónoma de México, 1988. 
Solano, Francisco. Documentos sobre politica lingüistica en Hispanoamérica (1492-1800). Madrid: CSIC, 1992.

Schmidel, Ulrich. Relatos de la conquista del Río de la Plata y Paraguay 1534-1554. Prólogo [traducción] y notas de Klaus Wagner. Madrid: Alianza Editorial, 1986.

Tabernero, Cristina. "Indigenismos y nivelación léxica del español americano en los siglos XVI y XVII." Alpha, 33 (2011): 215-233.

Tavárez, David. "Naming the Trinity: From Ideologies of Translation to Dialectics of Reception in Colonial Nahua Texts, 1547-1771." Colonial Latin American Review, 9:1 (2002): 21-47.

Vaquero de Ramírez, María Tránsito. "Español de América y lenguas indígenas.” Estudios de Lingüistica, 7 (1991): 9-26.

Weinreich, U., y Martinet, A. Languages in contact: Findings and problems. New York: Mouton, 1979.

Westall, Debra. "El contacto entre culturas: las manifestaciones lingüísticas." ASELE, Actas XII, 2001.

Zamora Munné, Juan Clemente. Indigenismos en la lengua de los conquistadores. Río Piedras: Editorial Universitaria de Puerto Rico, 1976.

. "Indigenismos en la lengua de los conquistadores." Hesperia: Anuario de filología hispánica, No 5 (2002): 195-210.

Zamora Munné, Juan C., y Jorge M. Guitart. Dialectología hispanoamericana: Teoría, descripción, historia. $2^{\mathrm{a}}$ rev. ed. Vol. 3. Salamanca: Colegio de España, 1988.

Zimmermann, Klaus. "Aspectos teóricos y metodológicos de la investigación sobre el contacto de lenguas en Hispanoamérica”. Klaus Zimmermann (ed.), Lenguas en contacto en Hispanoamérica. Madrid: Biblioteca Iberoamericana (1995): 9-34.

. "La construcción ecolingüísitica del contacto de lenguas (español y lenguas amerindias)". Yolanda Congosto Martín y Elena Méndez García de Paredes (eds.). Variación lingüística y contacto de lenguas en el mundo hispánico: in memoriam Manuel Alvar, vol. 27.Madrid; Frankfurt; Iberoamericana (2011): 361-388. 